\title{
THERMAL DIFFUSION AS A PURIFICATION TOOL
}

\author{
R. K. Prabhudesai* and J. E. Powers \\ University of Michigan, Ann Arbor, Mich.
}

\section{Introduction}

In the field of physical sciences and in chemical process technology, the purification of materials is very often most important. In many situations conventional processes such as distillation and crystallization are not applicable as in the case of closely boiling liquids, organic dyes, biologicals and colloids. In such cases, the less conventional techniques assume a great importance. Of the many unusual techniques, thermal diffusion, which is based on the fact that application of a temperature gradient on a homogeneous solution establishes a concentration gradient, has been widely investigated both theoretically and experimentally. Because of its special application it continues to receive considerable attention from researchers as a tool of purification in spite of the fact that it is an expensive process. In the present paper, it is proposed to briefly discuss some aspects of thermal diffusion as a purification technique.

\section{Thermal Diffusion Equipment}

Since its observation, thermal diffusion has been carried out in two broad types of equipment: $(a)$ static cells in which natural convection is avoided, and $(b)$ Clusius-Dickel thermogravitational columns in which use is made of the natural convection to enhance the separation.

Convection-free static cells are primarily utilized to determine the thermal diffusion factor $\alpha$. In these cells, the temperature gradient is applied in such a manner that convection is inhibited. Static equipment as proposed by Tanner ${ }^{1}$ is constructed of horizontal flat plates with the hot plate on the top and the cold plate at the bottom (FIGURE $1 a$ ). The principle of operation of this cell is very simple. Because of the temperature difference between top hot plate and bottom cold plate, one component (usually the lighter) migrates towards the hot plate due to thermal diffusion and concentrates there while the other one concentrates in the region of the bottom plate. The migration due to thermal diffusion is opposed by ordinary diffusion in reverse direction. Decreasing the plate distance helps to inhibit the convective remixing and also decreases the time required to reach steady state conditions.

Other investigators have attempted to minimize convective remixing by localizing the temperature gradient and the resulting separation. Riehl ${ }^{2} \mathrm{em}$ ployed a permeable membrane (FIGURE $1 b$ ) and Huse, Trevoy and Drick-

*IST Postdoctoral Fellow, Department of Chemical Engineering, University of Michigan, Ann Arbor, Mich. 

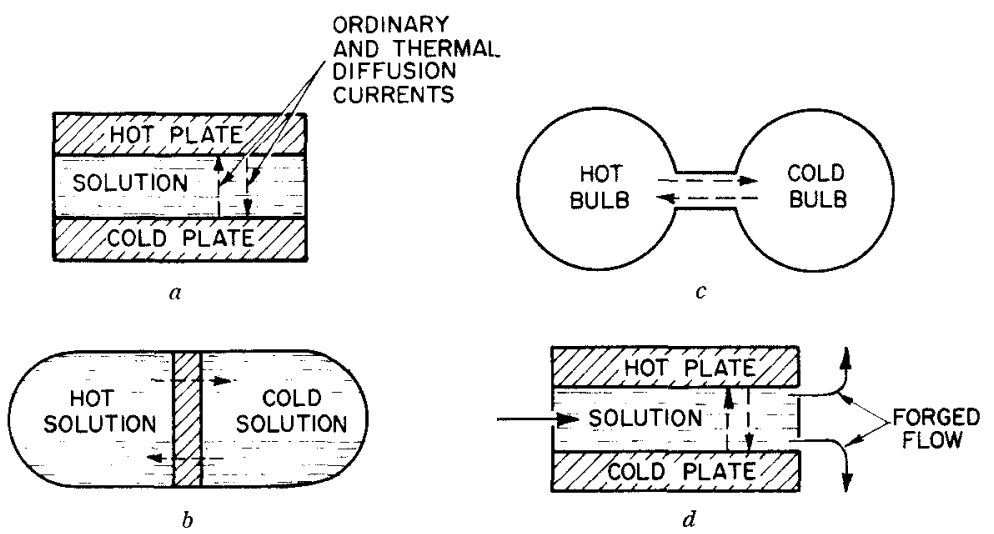

FIGURE 1. Static thermal diffusion equipment.

$a$. Horizontal flat plates without bulk flow.

$b$. Two bulb apparatus.

c. Agitated cell.

$d$. Horizontal flat plates with bulk flow.

amer $^{3}$ used a fritted glass disk to separate the hot and cold regions. Mixing in hot and cold regions is provided by magnetic stirrers. The localization of both temperature and concentration gradients in a membrane or fritted glass disk permits operation of the cell with a horizontal temperature gradient. For gas systems a two bulb apparatus (FIGURE 1c) as introduced by Chapman and Dootson ${ }^{4}$ is often used. The static method has been adopted for continuous separation ${ }^{5}$ by allowing material to flow between the two horizontal flat plates (FIGURE 1d).

In contrast to the above static convection free cells, thermogravitational columns as suggested by Clusius and Dickel $^{6}$ are capable of increasing the separation in a single equipment tremendously because the convective flow induced by the thermal gradient produces a cascading effect which multiplies separation otherwise obtainable. The principle of a thermogravitational column is illustrated in FIGURE 2. The thermogravitational column consists of two metal surfaces, one hot and another cold arranged vertically, the fluid mixture to be separated being held in between them. Because of the temperature gradient a net transport of one of the components occurs towards the hot wall which gives rise to a concentration gradient. Natural convection in the fluid mixture occurs primarily because of changes in density due to temperature but in some cases the effect of concentration gradient may also be of substantial magnitude. The thermogravitational column can be essentially considered as a vertical plate cell to multiply separation effect by refluxing. It is not unusual to multiply the separation effect by 1000 times or more by such arrangement as compared with static convection free cells. 


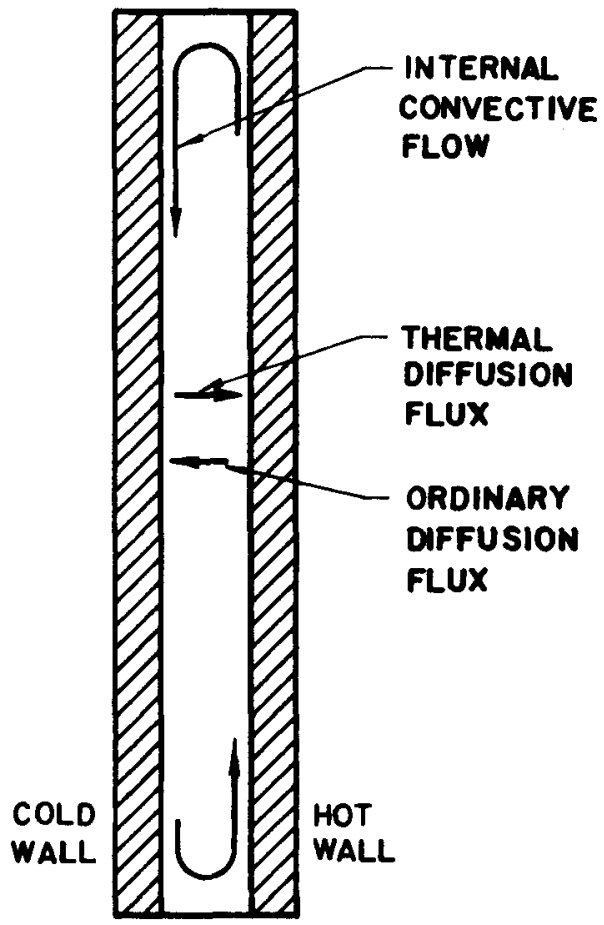

FIGURE 2. Principle of thermogravitational reflux.

The original Clusius-Dickel column was a hot wire column with reservoirs (FIGURE $3 a$ ). This column was very simple in operation and very effective. Clusius and Dickel showed the effectiveness of their column by obtaining chlorine isotopes ${ }^{6}$ in very high purity.

Modifications of the original hot wire thermogravitational column were proposed soon after its introduction. A central calrod heater is sometimes used in place of the hot wire. Much laboratory equipment in use today is made of concentric tubes with external electrical heating (FIGURE $3 b$ ). Some equipment mainly for liquid separation is constructed of flat plates (FIGURE $3 c)$.

A few points regarding plate and cylindrical columns are worth mentioning. The plate columns offer a certain degree of flexibility in their use since one can change the angle of their inclination with the horizontal and also the plate distance between hot and cold walls if desired. The possibility of changing plate spacing is especially useful since this is a very important factor affecting the degree of separation. One major problem with flat plate vertical columns is their bowing which causes serious adverse effects. Most investigators, therefore, have used concentric cylinder equipment. 

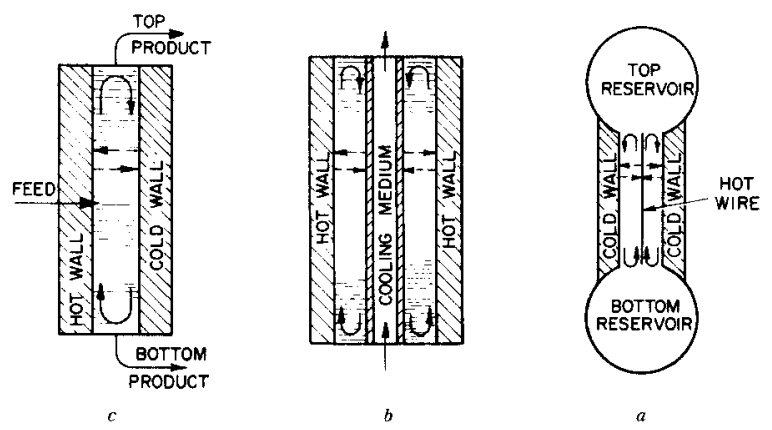

FIGURE 3. Thermogravitational thermal diffusion equipment.

a. Continuous-flow plate column.

$b$. Concentric-cylinder batch column without reservoirs.

c. Hot wire column with reservoirs.

Concentric cylinder apparatus allows use of condensing vapors or electrical heating. The construction of concentric cylindrical column is simpler than that of hot wire columns. A drawback of hot wire columns is vibration of the hot wire which causes back mixing. A comparison of hot wire columns with concentric type cylindrical columns is made by Jones and Furry.

Commercial concentric cylindrical columns can be purchased, easily installed and connected to tap water and electricity to put into operation. One such column ${ }^{8}$ is equipped with 11 sample taps for withdrawing liquid samples and is found to perform very well in separation of liquids.

Thermogravitational columns with reservoirs are generally operated in a batch manner but can also be operated in continuous manner for liquid phase separation as suggested by Brock ${ }^{9}$ and Frazier. ${ }^{10}$ The vertical columns without reservoirs can be operated in batch or continuous flow manner and are generally fed somewhere between the top and the bottom.

In order to improve the degree of separation achieved in a single thermogravitational column, a number of devices have been tried. Such attempts include tilting flat plates $(11,12)$, rotating columns of special construction $(13,14)$, insertion of packing $(15,16)$, and systems of baffles $(17,19)$. Although some of the above devices did increase the degree of separation at lower flow rates, the separation is adversely affected with larger throughputs. The added complexity of construction of the column with such devices, therefore, offsets the advantage of higher degree of separation that is obtained over a very limited range of small flow rates. Hence, the single hot wire and the concentric tube columns are the standard laboratory equipment.

Reflux can also be provided by forced convection with the external pumping as is done in horizontal thermal diffusion column by Jury and Von Halle. ${ }^{20}$ In this column (FIGURE 4), two streams one above the other and separated by a permeable membrane, flow counter-current to each other while 


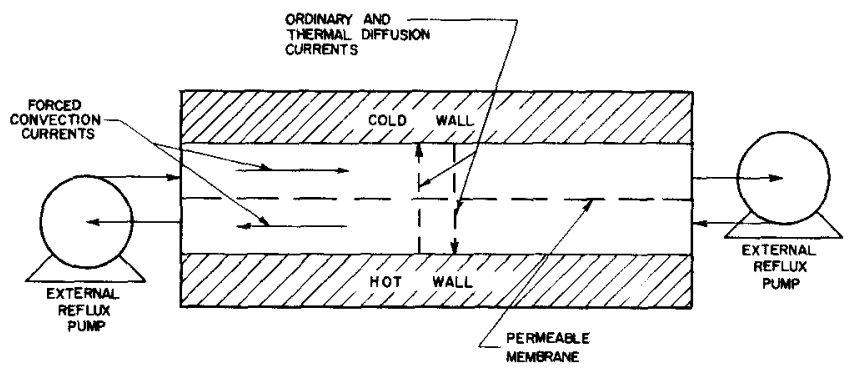

FIGURE 4. Horizontal thermal diffusion column of Von Halle. ${ }^{20}$

a vertical temperature gradient provides the separation potential. This column can be operated either with total reflux or with continuous product removal. This provides flexibility of operation and eliminates the so-called "forgotten effect" and therefore this apparatus is claimed to be particularly suitable to study the thermal diffusion coefficient in liquids.

For large scale preparation and to reduce the time required for a desired separation one requires generally a multicolumn cascade. One such multicolumn arrangement as suggested by Jones and Furry ${ }^{7}$ is shown in FIGURE 5.

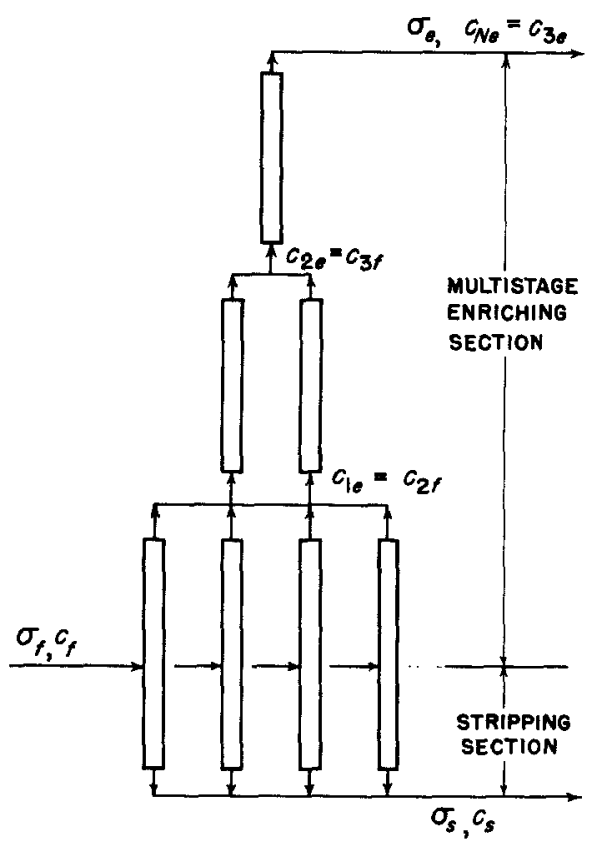

FIGURE 5. Multicolumn cascade, Furry and Jones. ${ }^{7}$ 
Theoretical Considerations. An intelligent application of thermal diffusion as a method of purification requires the understanding of the factors which influence the separation either in static cells or the thermogravitational columns. A considerable amount of theoretical and practical work has been done on thermal diffusion columns.

Thermal diffusion in binary systems has been studied more extensively both theoretically and experimentally. For this purpose, the thermal diffusion factor $\alpha$ for a binary system is defined by the flux equation:

$$
\mathrm{J}_{x-T D}=\rho\left(\frac{\alpha \mathrm{D}}{\overline{\mathrm{T}}}\right) \mathrm{C}(1-\mathrm{C}) \frac{\mathrm{dT}}{\mathrm{dx}}
$$

One aspect of thermal diffusion studies is concerned with the determination of $\alpha$ defined by equation 1 while the other is the application of basic principles of mass, heat and momentum transfer to predict the performance of the thermal diffusion equipment.

The Thermal Diffusion Constant $\alpha$. The thermal diffusion constant $\alpha$ for gases can be treated quantitatively by kinetic theory. Earlier theories were developed by assuming the gas molecules to follow Frankel's simple inverse power relation but more refined methods based on Lennard-Jones or exponential-six potential models are now available. For detailed discussion of these methods the reader is referred to the monograph by Grew and Ibbs ${ }^{21}$ and to the papers of Jones and Furry, ${ }^{7}$ Mason, ${ }^{22}$ and Saxena ${ }^{23}$ and others. Although the thermal diffusion effect has been quantitatively treated by kinetic theory, the cage model is capable of describing thermal diffusion effects in liquids only qualitatively. For more successful methods for the calculations of $\alpha$ for liquids, the reader is referred to the paper of Dougherty and Drickamer. ${ }^{24}$

In general the kinetic theory has provided an accurate description of the gaseous state. The thermal diffusion constant $\alpha$ can be estimated rather with some accuracy for gas mixtures composed of molecules having relatively simple collisions. This is especially true of isotopic gas mixtures. Theoretical attempts to predict $\alpha$ in the case of nonisotopic gas mixtures have produced some agreement between theory and experiment but all attempts at determination of $\alpha$ for liquid mixtures have met with limited success. In a qualitative manner, it can be noted that the thermal diffusion effect depends upon the relative size and shape of the species to be separated and that in the absence of any appreciable size difference, the heavier species almost always concentrates in the cold region. For substances of identical molecular weight the large molecule will go to the cold region. The mass effect is generally dominant for gas mixtures but for liquids the size factor appears to be of primary importance.

Phenomenological Theories of Thermal Diffusion Equipment Batch Static Cells. Until the introduction of the thermogravitational column thermal diffusion apparatus was operated so as to eliminate convection. The horizontal 
flat plate static cell and the two bulb apparatus are typical of such apparatus. Both are amenable to mathematical analysis. In static cells when a temperature gradient is applied to a portion of the solution, it gives rise to a flux of a component given by:

$$
\mathrm{J}_{x}=\rho \mathrm{D}\left[\left(\frac{\alpha}{\overline{\mathrm{T}}}\right) \mathrm{C}(1-\mathrm{C}) \frac{\mathrm{d} \mathrm{T}}{\mathrm{dx}}-\frac{\mathrm{dC}}{\mathrm{dx}}\right]
$$

This general flux expression has been used to determine the degree of separation in a static cell and the time of relaxation. No details will be given here since an excellent summary of such application is available elsewhere. ${ }^{25}$ Here it is sufficient to make a few observations. Assuming $\alpha$ is constant, the integration of equation 2 yields a general expression for the steady state separation:

$$
\mathrm{C}_{H}\left(1-\mathrm{C}_{C}\right) /\left[\mathrm{C}_{C}\left(1-\mathrm{C}_{H}\right)\right]=\left(\mathrm{T}_{H} / \mathrm{T}_{C}\right)^{\alpha}
$$

from which it is evident that the steady state separation in static cells is a function of hot and cold wall temperatures and the thermal diffusion coefficient $\alpha$ and is altogether independent of the plate spacing.

The analysis of transient behavior of static cells is rather more complicated. The basic approach to the transient analysis differs considerably for different types of static cells. The results of such analyses show however that the final approach to steady state in many types of thermal diffusion equipment is exponential and is given by (for $t>>t_{r}$ )

$$
\mathrm{f}=\frac{[\mathrm{C}(\mathrm{t})-\mathrm{C}(\mathrm{O}, \mathrm{t})]}{[\mathrm{C}(l, \infty)-\mathrm{C}(0, \infty)]}=1-\mathrm{ce}^{-t / t}
$$

where

f -fractional approach to equilibrium

$l$-characteristic length of apparatus

c - a constant

$\mathrm{t}$ - time

$t_{r}-$ relaxation time, i.e., the time required to obtain $(1-c / e)$ of the equilibrium separation.

Several authors ${ }^{25}$ have obtained expressions for relaxation time $t_{r}$ for different types of apparatus. One such solution is given by Von Halle ${ }^{25}$ and is:

$$
t_{r}=\frac{l^{2}}{\mathrm{D}\left(\pi^{2}+\frac{\alpha \Delta \mathrm{T}}{2 \overline{\mathrm{T}}}\right)}
$$

It may be observed here that for a flat plate cell, in contrast to steady state separation, the relaxation time $t_{r}$ is a function of the geometry of the apparatus as represented by plate spacing $l$, the thermal diffusion constant $\alpha$, the temperature difference and the average temperature $\overline{\mathrm{T}}$. 


\section{Phenomenological Description of Thermogravitational Columns}

For the phenomenological description of thermograviational columns, several theories differing mainly in rigor of analysis have been proposed. The one largely used is the procedure originally proposed by Furry, Jones and Onsager. ${ }^{26}$ This procedure involves three major steps: First, by a material balance consideration involving the horizontal thermal diffusion flux, the horizontal and vertical ordinary diffusion fluxes and the vertical convective velocity, a nonlinear partial differential equation is obtained relating concentration with position coordinates for the column and time. The second step involves consideration of the net transport of one component of the binary system passing through a plane perpendicular to the walls of a batch thermal diffusion column. This transport is the net result of the combination of vertical convection and diffusion. The third step involves the reduction of the general nonlinear partial differential equation for batch case with appropriate boundary conditions and combining it with the expression for the transport with the help of velocity profile to yield the final transport equation:

$$
\tau=\mathrm{HC}(1-\mathrm{C})-\left(\mathrm{K}_{\mathrm{c}}+\mathrm{K}_{d}\right) \frac{\mathrm{dc}}{\mathrm{dy}}
$$

with the definition:

$$
\mathrm{K}=\mathrm{K}_{\mathrm{c}}+\mathrm{K}_{\boldsymbol{d}}
$$

in which $\mathrm{H}, \mathrm{K}_{\mathrm{c}}$ and $\mathrm{K}_{d}$ are the transport coefficients which are functions of the physical properties of the system, plate spacing, column geometry and temperature difference. In an attempt to improve column phenomenological theory, Saxena and $\operatorname{Raman}^{27}$ have rederived very rigorously the transport equation for the cylindrical case for gases, which differs from that of Jones and Furry in the inclusion of an additional term $\mathrm{K}_{d}^{\prime}$ in $\mathrm{K}$. However, these authors conclude that the present form of column theory cannot be extended with any confidence for predicting the column behavior either for pure polyatomic gases or their mixtures.

In order to use equation 6 , it is necessary to obtain column transport coefficients $\mathrm{H}, \mathrm{K}_{\mathrm{c}}$ and $\mathbf{K}_{d}$. This has been done for different types of thermal diffusion equipment. For plate columns, the transport coefficients are obtained with the assumption of constant $\alpha$ and the physical properties $\mathrm{D}, \rho, \eta$ and are given by:

$$
\begin{gathered}
\mathrm{H}=\mathrm{B} \rho\left(\frac{\mathrm{g} \beta_{T} \Delta \mathrm{T}}{\eta}\right) \frac{\alpha \Delta \mathrm{T}}{\mathrm{T}} \frac{(2 \omega)^{3}}{6 !} \\
\mathrm{K}_{c}=\frac{\mathrm{B} \rho}{\mathrm{D}}\left(\frac{\mathrm{g} \beta_{T} \Delta \mathrm{T}}{\eta}\right)^{2} \frac{(2 \omega)^{7}}{9 !}
\end{gathered}
$$


and

$$
\begin{aligned}
& \mathrm{K}_{d}=2 \omega \mathrm{DB}_{\rho} \\
& \mathrm{K}=\mathrm{K}_{\mathrm{c}}+\mathrm{K}_{d}
\end{aligned}
$$

In case of many liquid systems where properties change little with temperature the above expressions are adequate. However, for gaseous systems and for cylindrical geometry of the column, the above expressions are inadequate. In case of gases, $\alpha$ and the properties $\mathrm{D}, \eta$ and $\rho$ are strong functions of temperature and therefore the variation in properties of the system with respect to both temperature and position in the column, as also the temperature dependence of $\alpha$, have to be taken into account.

The corrections to be applied in case of hot wire and concentric cylinder type apparatus were obtained by Jones and Furry for Maxwellian gases. ${ }^{7}$ Further improvement in the calculation of column transport coefficients for gaseous systems has been made by McInteer and Reisfield. ${ }^{28}$ Von Halle and E. Greene,$^{29} \mathrm{G}$. Reinhold ${ }^{30}$ obtained exact derivation of transport equation for a concentric cylinder apparatus and obtained column transport factors for special values of inverse power potential by numerical solution of the transport equation. The expressions obtained by Von Halle and Greene ${ }^{29}$ are extremely useful and are given by:

$$
\begin{gathered}
\mathrm{H}=\left(\frac{2 \pi}{6 !}\right)\left(\frac{\alpha \rho^{2} \mathrm{~g}}{\eta}\right)_{1} \mathbf{r}_{1}^{4} \mathbf{h}\left(\mathrm{T}_{2} / \mathrm{T}_{1}, \mathbf{r}_{1} / \mathbf{r}_{2}\right) \\
\mathrm{K}_{c}=\left(\frac{2 \pi}{9 !}\right)\left(\frac{\rho^{3} \mathrm{~g}^{2}}{\eta \mathrm{D}}\right)_{1} \mathbf{r}_{1}^{8} \mathbf{k}_{d}\left(\mathrm{~T}_{2} / \mathrm{T}_{1}, \mathrm{r}_{1} / \mathrm{r}_{2}\right) \\
\mathrm{K}_{d}=(2 \pi) \quad(\rho \mathrm{D})_{1} \mathrm{r}_{1}^{2} \mathbf{k}_{d}\left(\mathrm{~T}_{2} / \mathrm{T}_{1}, \mathrm{r}_{1} / \mathbf{r}_{2}\right) \\
\mathrm{K}=\mathrm{K}_{c}+\mathrm{K}_{d}
\end{gathered}
$$

In the above equations $\mathrm{h}, \mathrm{k}_{\mathrm{c}}$ and $\mathrm{k}_{d}$ are the column shape correction factors which have been tabulated extensively by Von Halle and Greene. ${ }^{29}$

In general, the theoretically calculated values of the transport coefficients $\mathrm{K}, \mathrm{K}_{\mathrm{c}}$ and $\mathrm{K}_{d}$ are not in quantitative agreement with the experiment. In order to obtain a quantitative agreement between theoretically calculated separations and the experimentally observed separations under identical conditions, the theoretical values of $\mathrm{H}$ and $\mathrm{K}$ are required to be modified empirically. Two such modifications have been proposed. One is based on data obtained primarily with gaseous systems ${ }^{31}$ while the other is applicable to data on liquids..$^{32}$ In practice one corrects the column transport coefficients for the effect of the parasitic remixing by addition of a term " $\mathrm{K}_{p}$ " in equation 7 on its righthand side. $K_{p}$ must be empirically determined for a given equipment and system under study. At present no theoretical development is available by which $\mathbf{K}_{p}$ could be predicted. 


\section{Applications of Transport Equation}

If the values of transport coefficients $H$ and $K$ for a given type of equipment and for a given liquid or gaseous system under a given set of conditions of column parameters such as plate spacing and temperature difference are obtained, the transport equation 6 can be conveniently used to treat a variety of thermogravitational column operations. FJO procedure of obtaining the transport equation is undoubtedly approximate but it yields for the transport of component in the column a simple nonlinear differential equation which is not only capable of analytical solution but of varied manipulation as well. It, thus, allows simplified mathematical treatment of thermogravitational thermal diffusion equipment.

Thus, even though obtained by the consideration of batch operation of the column, it has been used to describe the operations of the following:

(a) Transient and steady state batch columns with or without reservoirs; ${ }^{20}$

(b) Continuous-flow columns without reservoirs; ${ }^{32}$

(c) Transient batch and continuous-flow columns without reservoirs with horizontal or vertical barriers; $;^{33.34}$

(d) Packed columns; ${ }^{35}$

(e) To account for the effect of sample withdrawal in the study of transient batch operation of the column. ${ }^{36}$

For example, in the case of continuous flow operation of the column the flow through the column is accounted for by imposing a linear transport in the vertical direction as suggested by Jones and Furry ${ }^{7}$ which yields the modified transport equation for flow case:

$$
\tau=H C(1-C)-K \frac{d C}{d y}+\sigma C
$$

It is beyond the scope of the present paper to describe in detail these many applications of the transport equation to predict and interpret the experimental data on thermogravitational columns. Only a few observations will be made here regarding the theoretical development and the analysis of the experimental results.

It will be seen that there are two types of factors involved in the transport equation, which affect the separation obtained in a thermogravitational column. These factors are: $(a)$ column length and flow rate on one hand and (b) parameters such as temperature difference, plate spacing, pressure, angle of inclination of the column, and thermal diffusion factor $\alpha$, which are associated with column transport coefficients $H, K_{c}$ and $K_{d}$. The effects of these factors on the operation of a thermogravitational column have been concisely discussed by Powers. ${ }^{25}$ Here only a few general remarks will be made concerning the effect of a few of the important parameters on the separations obtained. 
The comparison of theory and experiment is facilitated by considering the solution of the transport equation and calculated separation therefrom. It was found more convenient by different authors to modify the transport equation by replacing the product term $\mathrm{C}(1-\mathrm{C})$ by an approximate expression so as to linearize the differential equation. The resulting simple differential equation is easy to handle for various cases of the column operation and can also be used to conveniently treat the transient case. By considering one such approximate solution of the transport equation, the effect of various parameters on the separation will now be considered.

For binary systems the batch steady separation is obtained by putting $\tau=0$ in equation 6, and integrating the resulting equation and is given by

$$
\ln \mathbf{q}_{e}=\ln \left[(\mathrm{C} /[1-\mathrm{C}]) /(\mathrm{C} /[1-\mathrm{C}])_{s}\right]=\frac{\mathrm{HL}}{\mathrm{K}}
$$

Equation 15 predicts the separation as measured by $\ln \mathrm{q}_{e}$ to be directly proportional to the column length. Results of several investigators ${ }^{37.38}$ indicate that the effect of column length is as predicted by theory as is illustrated in FIGURE 6. However, some deviations from the theoretical relation between

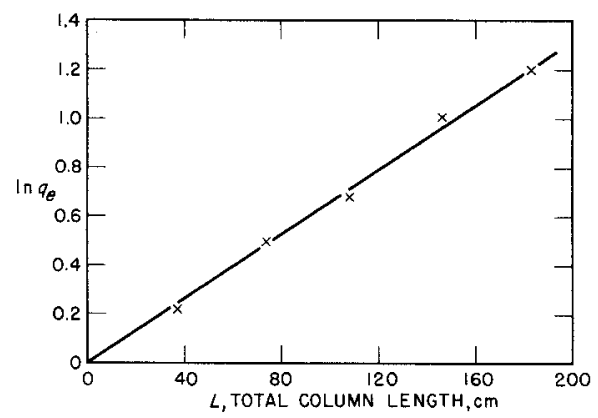

FIGURE 6. Effect of column length on equilibrium separation, Crownover and Powers. ${ }^{38}$

length and separation as given by equation 15 have been observed..$^{39,40}$ Fleming ${ }^{34}$ especially found that at short column lengths, the end effects were pronounced.

The steady state separation given by equation 15 can be rewritten in the form

$$
\ln \mathbf{q}_{e}=\frac{\mathrm{a} \Delta \mathrm{T}^{2}}{\mathrm{~b} \Delta \mathrm{T}^{2}+\mathrm{K}_{d}}
$$

For liquid systems, the term $\mathrm{K}_{d}$ is negligibly small and hence from equation 16, it is seen that the steady state batch separation as measured by $\ln \mathbf{q}_{e}$ is 


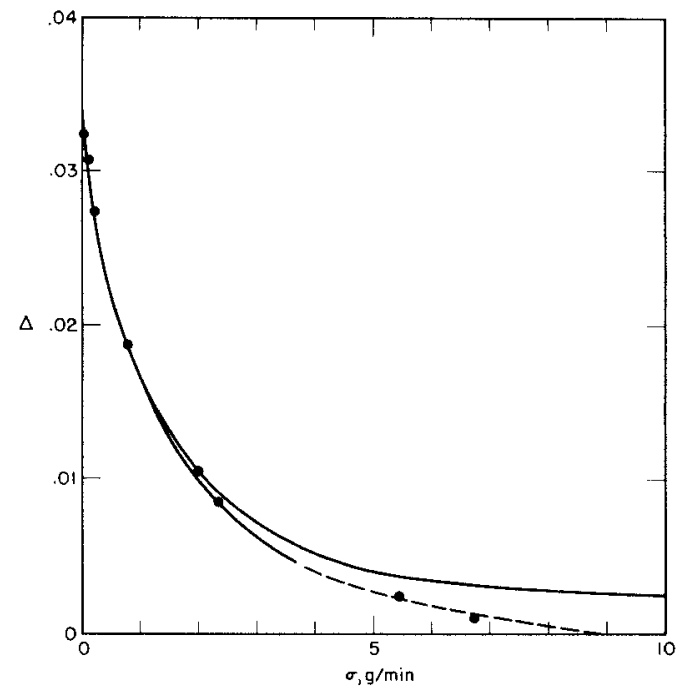

FIGURE 7. Effect of flow rate through the column on separation, Powers. ${ }^{32}$

independent of $\Delta \mathrm{T}$. Results obtained by Powers ${ }^{32}$ on various liquid systems and in a number of different columns are presented in FIGURE 7 . The two lines in the figure are almost parallel to $\Delta \mathrm{T}$ axis which shows that the separations are independent of $\Delta T$.

Effect of plate spacing is by far the most important because it enters the theoretical expressions for $\mathrm{H}$ and $\mathrm{K}_{\mathrm{c}}$ as 4 th and 7 th power. The effect of plate spacing on separation is presented in FIGURE 8 . The data indicate a qualitative agreement between theory and experiment. The range of plate

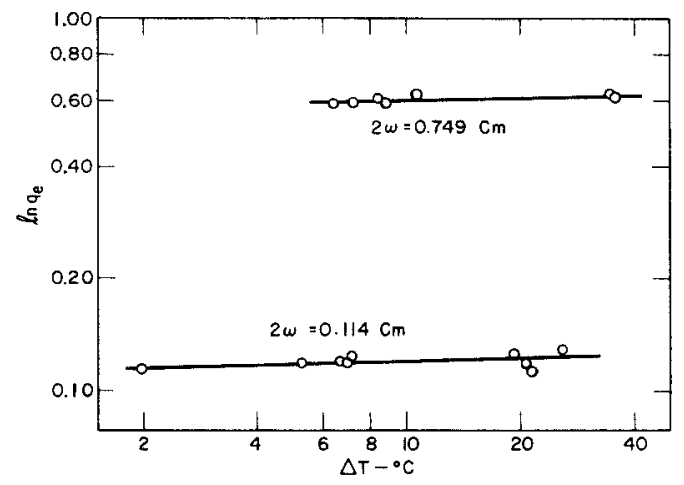

FIGURE 8. Effect of temperature difference on equilibrium separation in liquids, Powers. ${ }^{32}$ 
spacings that can be used effectively is very much restricted. In columns separating liquid mixtures, plate spacings from $0.02 \mathrm{~cm}$ to $0.026 \mathrm{~cm}$ have been reported. With such small spacings, it is essential to maintain the uniformity of the spacing. Existence of optimum plate spacing in thermal diffusion has been shown. ${ }^{41}$

Solution of the transport equation $\mathbf{1 4}$ for the case of continuous flow operation of a thermogravitational column yields an exact general solution relating the concentrations at the end of the column to the flow rate $\sigma$ through the column and the transport coefficients $\mathrm{H}$ and $\mathrm{K} .{ }^{25}$ The complicated form of this general solution has led to the development of several restricted solutions as presented by Jones and Furry. ${ }^{7}$ One such restricted solution for the case of $\mathrm{C}(1-\mathrm{C})=\mathrm{a}$ and with equal flow rates in the enriching and stripping sections of the column, is given by

$$
\Delta=\mathrm{C}_{e}-\mathrm{C}_{s}=\frac{4 \mathrm{aH}}{\sigma_{F}}\left[1-\mathrm{e}^{-\sigma_{F} L / 4 K}\right]
$$

where $\Delta$ is the steady state separation. The experimental data show that the separation decreases with flow rate as predicted by the theory. The experimental data agree with theoretical results quite well at low flow rates as shown by the dark line in the FIGURE 9 , but at higher flow rates corrections have to be applied to $H$ and $K$ as suggested by Powers and Wilkes. ${ }^{12,32}$ In FIGURE

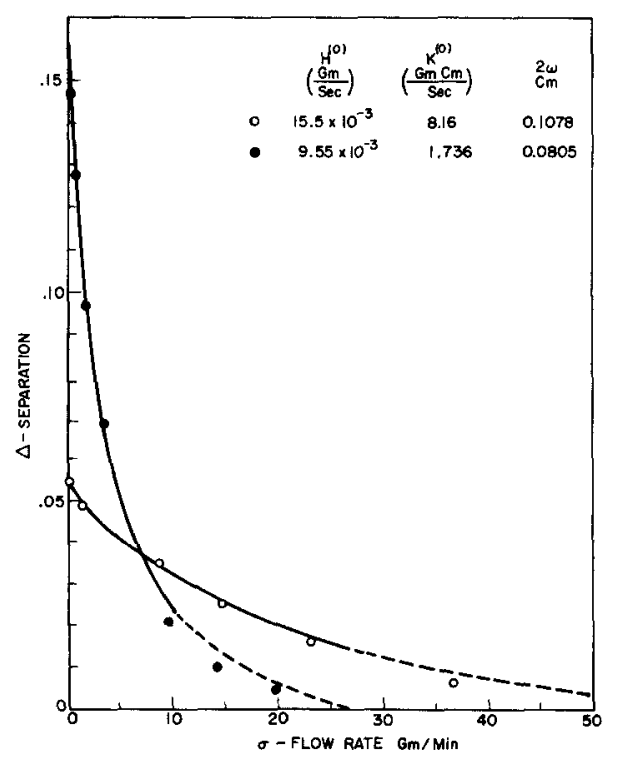

FIGURE 9. Effect of plate spacing on separation in liquids, Powers. ${ }^{32}$ 


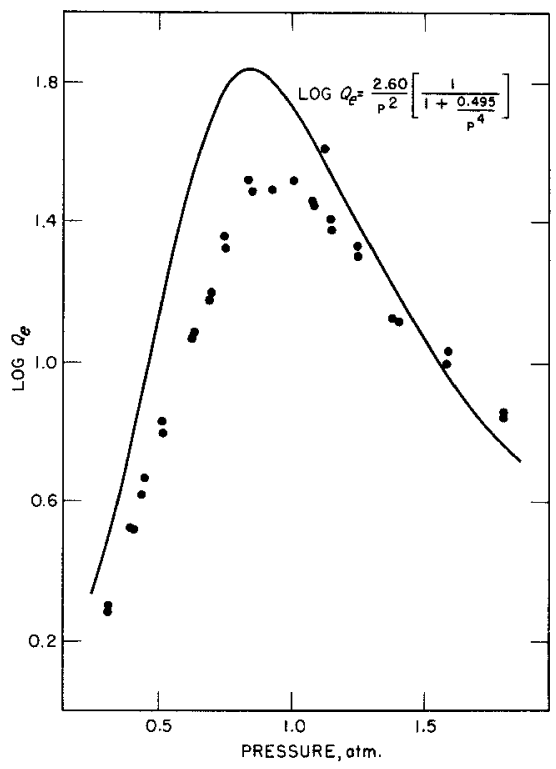

FIGURE 10. Effect of pressure on equilibrium separation in gases, Drickamer et al. ${ }^{43}$

8 , the dotted line indicates the theoretical results that were obtained using correlations for the effect of flow rate.

The pressure is an important variable in case of separation of gaseous mixtures. The theory predicts a maximum in $q_{e}$ with respect to pressure. Several investigators ${ }^{42,43}$ have demonstrated that such a maximum exists. FIGURE 10 is reproduced from a publication by Drickamer et al ${ }^{42}$ to illustrate the nature of agreement between theory and experiment. It will be seen from this figure that the equilibrium separation factor goes through a maximum with increase in $\mathrm{P}$.

Mathematical analysis of transient behavior of thermogravitational column using transport equation is rather complicated than the corresponding static case. However, analyses of some special cases are available. ${ }^{25}$ The results of experimental data of Powers ${ }^{44}$ are shown in FIGURE 11. It will be seen from FIGURE 11 that the separation attains a steady state value as time increases and that even for comparatively small separation (30 per cent) relatively long times are required.

\section{Theory of Multicomponent Separation}

Theory of multicomponent gas separation has been worked out by Valk. ${ }^{45}$ He found satisfactory agreement between theory and experiment. Vries and Larangeira ${ }^{46}$ carried out thermal diffusion experiments with several ternary 


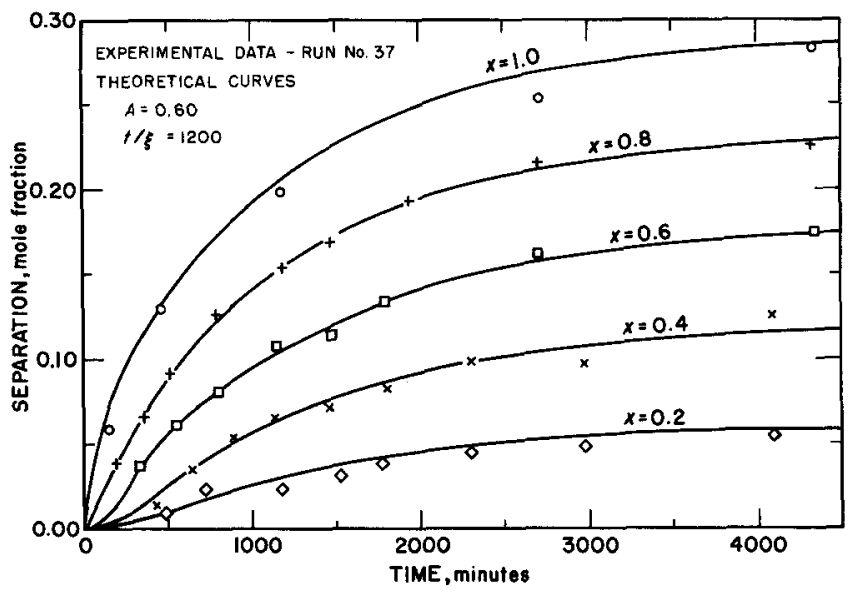

FIGURE 11. Approach to equilibrium in a thermogravitational column, Powers. ${ }^{44}$

mixtures (e.g., $\mathrm{Ar}^{36}-\mathrm{Ar}^{40}-\mathrm{He}$ ), $\mathrm{Ar}^{36}-\mathrm{Ar}^{40}-\mathrm{Ne}, \mathrm{Ne}^{20}-\mathrm{Ne}^{22}-\mathrm{H}$, etc.) in which a third component $(\mathrm{H}, \mathrm{Ne}, \mathrm{H})$ was added to influence the separation of desired species. They concluded that the influence of the third component on the separation of a binary mixture cannot always be predicted.

\section{Design of Thermal Diffusion Equipment}

For carrying out a desired separation of a given gaseous or liquid mixture by thermal diffusion, one has to consider several factors. These include the type of equipment (static cells, concentric, hot wire, plate, column multiple column cascade), and mode of operation (transient or steady state). Another important factor is the selection of efficient values of column transport coefficients $H$ and $K$ which in turn depend upon the values of $T_{H}$ and $T_{C}$, and the best value of plate spacing in planar case and the radii in the case of cylindrical apparatus. A proper choice of equipment and the selection of conditions of operation of the same will depend mainly upon the required degree of separation and the time in which it is required. Reproducibility of the results, as also the desired average concentration of the sample, are important considerations. The cost of operating an apparatus even on small scale might entail large expenditures because of the high heat requirements of the thermal diffusion process and therefore due consideration must be given to the operating as well as capital cost.

In sizing the thermal diffusion equipment due consideration must also be given to the effect of parasitic remixing which causes an increase in $K$ and hence reduction in the attainable separation. To offset this adverse effect and to bring theoretical value of $\mathrm{K}$ closer to its experimental value, $\mathrm{K}$ is modified empirically by increasing $K_{c}$ in equation 12 by 30 per cent ${ }^{7}$ for 
gaseous separations. For liquid mixtures empirical relations of Powers ${ }^{32}$ will be of use.

Great care needs to be taken in the design of the apparatus since once the column is built, there is little leeway in choosing the proper operational conditions. As many variables are involved, a theoretical study is quite necessary in each case to decide the feasability and the most efficient method of operation. It would be advisable to allow sufficient safety margin with respect to temperature and pressure so as to allow considerable variation in these after the apparatus is installed. The final design of the thermal diffusion apparatus for a particular separation will necessarily involve a compromise between the various factors. Krasney-Ergen ${ }^{47}$ has discussed the factors in optimum design of thermal diffusion column. Two published design illustrations will be of interest. For liquid mixtures the application of optimization procedure has been illustrated by Powers. ${ }^{32}$ Multicolumn design for gaseous separation has been discussed and illustrated with an example by Jones and Furry?

\section{Applications of Thermal Diffusion}

Laboratory Applications. Thermal diffusion technique has been mostly used on laboratory scale. TD effects separation where other methods fail and offers a valuable tool to produce practically pure materials such as the isotopes in both liquid and gaseous phase. The objectives of thermal diffusion experiments are generally to obtain thermal diffusion factors and thereby predict the nature of the intermolecular forces, properties such as viscosity, thermal conductivity and diffusivity and purifications of materials. Thermal diffusion separations have been carried out in gases, liquids and of electrolytes and dyes in solutions. Owing to pressure on space, it is not possible to compile here all the laboratory scale separations reported in the literature. For a detailed survey of the thermal diffusion work in liquids, gases and electrolytic solutions, excellent reviews by Von Halle, ${ }^{20}$ Eck $^{48}$ and Tetsuya Iida ${ }^{49}$ may be consulted. Here only a few illustrations will be given.

Thermal diffusion has been most successfully used to separate gaseous isotopes such as $\mathrm{He}^{3}, \mathrm{Xe}^{136}, \mathrm{C}^{13} \mathrm{H}_{4}, \mathrm{Ne}^{22}$, etc. It has been also used to effect separation in liquid phase, of isomers as well as the close boiling liquids. In most cases the heavier component concentrates at the cold wall. There exist very fascinating possibilities for the separation of multicomponent mixtures especially in liquid phase. Most of the multicomponent thermal diffusion has been tried with isotopic gas mixtures or liquid petroleum products.

Thus, Seelbach and Quakenbush ${ }^{50}$ fractionated fat and oil derivatives by thermal diffusion in a plate column and found that triglycerides concentrated at the top while monoglycerides come to the bottom. Other notable examples of separation of multicomponent mixtures by thermal diffusion are the separation of components of hydrogenated shale oil, fractionation of naptha, lube 
oil and various other petroleum oil stocks such as kerosene, light virgin gas oil, and slack wax.

A substantial amount of experimental work has been carried out on the determination of Soret coefficients for solutions of electrolytes such as a mixture of $\mathrm{NH}_{4}$ salts, ${ }^{51}$ and $\mathrm{CuSO}_{4}-\mathrm{COSO}_{4}-\mathrm{H}_{2} \mathrm{O}$ system. ${ }^{52}$ A survey of this work has been done by Von Halle. ${ }^{20}$

Large Scale Application of Thermal Diffusion. In few cases thermal diffusion has been employed for large scale preparation of certain expensive special materials. In 1945, a thermal diffusion plant of gigantic proportions was erected at Oak Ridge, Tennessee. In this plant ${ }^{41} \mathrm{U} 235$ as liquid $\mathrm{UF}_{6}$ was increased in abundance from 0.715 to 0.86 per cent and thereby 20 per cent increase in the output of the electromagnetic separation plant was realized at a cost of $\$ 20,000,000$. This plant was shut down within a year. From this exotic beginning conncected with United States nuclear program, thermal diffusion has been moved to commercial application in recent years. A great deal of experimental and pilot plant work has been carried out by the Standard Oil Co., Ohio. This research is primarily concerned with the production of lubricating oil with high viscosity index. A report by Grasselli, Plymale and Brown ${ }^{53}$ summarizes this work. Equipment costs have been reduced by using concentric cylinder columns in bundles within a shell as in shell and tube heat exchanger. A pilot unit was constructed. It was proposed that 10 units each containing 96 columns $34 \mathrm{ft}$. long could process 3300 gallons of lubricating oil per day. Equipment costs were predicted to be $\$ 110,000$, but the heating costs were so high that the project was abandoned.

Another recent report ${ }^{54}$ indicates that a rising demand for rare isotopes has focused attention on thermal diffusion for commercial application. At AEC's Mound Laboratories, Miamisburg, Ohio a five-column thermal diffusion plant is operated by Monsanto Research Corporation to produce high purity $\mathrm{He}^{3}$ (99 per cent or more) from a mixture of gases produced by nutron bombardment of Lithium 6. Total production in a year was $53 \mathrm{cu}$. $\mathrm{ft}$. (at standard conditions). Although $\mathrm{He}^{3}$ is the first and only product for sale $\left(\$ 5000 / \mathrm{ft}^{3}\right)$, extensive work is being carried out for other thermal diffusion separations of isotopes of Xenon, Neon, Argon, Krypton and Carbon.

\section{Conclusions}

Thermal diffusion is an expensive process and therefore as yet has found no widespread application. Since it is based on molecular interactions, size and shape factors, thermal diffusion should make a valuable tool for laboratory investigations and may serve as the basis for commercial separation. Static cells provide the most basic data on thermal diffusion effect. Such data will be useful to test the theories of gaseous and liquid states. Additional theoretical work is essential to improve thermal diffusion equipment. It might find application in fine chemical and pharmacutical fields where unit costs are often high. Thermal diffusion as applied to these fields should offer advantages 
because the process conditions are moderate, separation takes place without change of phase or addition of other agents. Thermal diffusion also allows complex mixtures to be separated into many distinct fractions and exploratory separations are easily made with a minimum of expense. However, it appears that large scale applications of thermal diffusion will be limited to some special applications as preparation of fine chemicals because of high heat requirements.

\section{Appendix}

Notation: Following are symbols used in equations in this paper.

a - a constant

b - a constant

C - concentration of component in mixture

C - subscript denoting "cold wall"

$\mathrm{C}_{c}$ - concentration of component at cold wall

$\mathrm{C}_{e}$ - concentration at the top of enriching section of solumn

$\mathrm{C}_{H}-$ concentration of component at hot wall

C. - concentration at the bottom of stripping section

c - a constant

D - diffusion coefficient; $\mathrm{cm}^{2} / \mathrm{sec}$

$\mathrm{D}_{I}$ - diameter of inner (hot) wall; $\mathrm{cm}$

g - acceleration due to gravity; $\mathrm{cm} / \mathrm{sec}^{2}$

f - fractional approach to equilibrium; dimensionless

$\mathrm{H}-$ parameter defined by equations 8 and $11 ; \mathrm{gm} / \mathrm{sec}$

$\mathrm{h}-$ numerical integration factor for $\mathrm{H}$ in equation 11; dimensionless

$\mathrm{K}$ - parameter defined by equation 7 ; gm-cm/ sec

$\mathrm{K}_{\mathrm{c}}$ - parameter defined by equation 10 and $12 ; \mathrm{gm}-\mathrm{cm} / \mathrm{sec}$

$\mathrm{K}_{d}-$ parameter defined by equation 10 and $13 ; \mathrm{gm}-\mathrm{cm} / \mathrm{sec}$

$\mathrm{K}_{p}$ - factor to be added to $\mathrm{K}$ to correct for parasitic remixing; $\mathrm{gm}-\mathrm{cm} / \mathrm{sec}$

$\mathrm{k}$ - thermal conductivity; $\mathrm{cal} / \mathrm{cm} \mathrm{sec}^{\circ} \mathrm{K}$

$\mathbf{k}_{c}$ - numerical integration factor for $\mathrm{K}_{c}$ in equation 12; dimensionless

$\mathbf{k}_{d}-$ numerical integration factor for $\mathbf{K}_{d}$ in equation 13; dimensionless

$\mathrm{L}$ - length of column; $\mathrm{cm}$

$l$ - characteristic length; $\mathrm{cm}$,

$\mathrm{P}$ - pressure in the column; atm

$\mathrm{q}_{e}$ - equilibrium separation factor; dimensionless

$\mathbf{r}_{1}$ - radius of cold wall; $\mathrm{cm}$

$r_{2}$ - radius of hot wall; $\mathrm{cm}$

$\mathrm{T}$ - absolute temperature; ${ }^{\circ} \mathrm{K}$

$\mathrm{T}_{C}$ - temperature of cold wall; ${ }^{\circ} \mathrm{K}$

$\mathrm{T}_{H}$ - temperature of hot wall; ${ }^{\circ} \mathrm{K}$

t - time; sec

$\mathbf{t}_{r}$ - time of relaxation; sec 
y - length coordinate; $\mathrm{cm}$

$\alpha \quad$ - thermal diffusion constant; dimensionless

$\beta_{T}$ - density coefficient with respect to temperature; $\mathrm{gm} / \mathrm{cm}^{3}-^{\circ} \mathrm{K}$

$\rho \quad$ density of fluid mixture; $\mathrm{gm} / \mathrm{cm}^{3}$

$\mu \quad$ - coefficient of viscosity; $\mathrm{gm} / \mathrm{cm} \mathrm{sec}$

$\eta \quad$ coefficient of viscosity; $\mathrm{gm} / \mathrm{cm} \mathrm{sec}$

$\tau$ - transport of component 1 up the column; $\mathrm{gm} / \mathrm{sec}$

$\Delta \mathrm{T}$ - temperature difference ${ }^{\circ} \mathrm{K}$

$\omega$-- plate spacing; $\mathrm{cm}$

$\sigma \quad$ flow rate through column; $\mathrm{gm} / \mathrm{sec}$

$\sigma_{F}-$ flow rate of feed to the column; $\mathrm{gm} / \mathrm{sec}$

$\Delta \quad$ - steady state separation

\section{References}

1. TANNER, C. C. 1927. Trans. Faraday Soc. 23: 75 .

2. RIEHL, Z. 1943. Electrochem. 49: 306.

3. HUSE, E. S., D. J. TREVOY \& H. G. DRICKAMER. 1950. Rev. Serv. Instr. 21: 60.

4. ChaPMAN, S. \& F. W. DOOTSON. 1917. Phil. Mag. 33 (6): 248.

5. JONES, A. L. Nov. 8, 1955. U. S. Patent 2723034.

6. CLUSIUS, K. \& G. DICKEL. 1938. Naturwissenschaften 26: 546.

7. JONES, R. C. \& W. H. FURRY. 1946. Rev. Mod. Phys. 18: 151.

8. M. M. FINK COMPANY, Brecksville, Ohio.

9. BROCK, J. R. 1961. Chem. Engr. Sci. 13: 207.

10. FRAZIER, DAVID. 1962. Ind. Engr. Chem. Proc. Design Develop. 1: 237-40.

11. CARR, H. E. 1944. J. Chem. Phys. 12: 349.

12. POWERS, J. E. \& C. R. WILKES. 1957. A. I. Ch. E. J. 3: 213.

13. FARBER, M. \& W. F. LIBBY. 1940. J. Chem. Phys. 8: 1965.

14. TILVIS, E. 1947. Soc. Sci., Fennica Commentationes Phys-Math. 13: 15.

15. SUlLIVAN, L. J., T. C. RUPPEL \& C. B. WILlingTON. 1955. Ind. Eng. Chem. 47: 208.

16. DEBYE, P. \& A. M. BUECHE. 1948. High Polymer Physics, Chemical Publishing Co., New York.: 497-527.

17. BREWER, A. K. \& A. BRAMLEY. October 14, 1941. U. S. Patent 2258594.

18. TREACY, J. C. \& R. E. RICH. 1955. Ind. Eng. Chem. 47: 1544.

19. DE MARIA, F. \& R. F. BENENATI. 1958. Ind. Eng. Chem. 50: 63.

20. JURY, S. H.\& E. VON HALLE. 1956. Chem. Eng. News. 34: 3606.

21. GREW, K. E. \& T. L. IBBS. 1952. Thermal Diffusion in Gases. Cambridge Univ. Press.

22. MASON, E. A., 1957. J. Chem. Phys. 27: 75-84, 782-90.

23. SAXENA, S. C. 1955. Indian J. Phys. 29: 131-40, 453-60.

24. DOUGHERTY, E. L. \& H. G. DRICKAMER. 1955. J. Chem. Phys. V. 23(2): 295-309.

25. POWERS, J. E. 1962. New Chem. Engr. Separation Techniques. Interscience Publishers, New York.: 1-96.

26. FURRY, W. H., R. C. JONES \& L. ONSAGER. 1939. Phys. Rev. 55: 1083-95.

27. SEXANA, S. C. \& S. RAMAN. 1962. Rev. Mod. Phys. 34(2): 252-66.

28. McINTEER, B. B. \& M. J. REISENFIELD. 1960. J. Chem. Phys. 33: 570-8.

29. Von Halle, E. \& E. GReEne. Sept. 1961. U. S. A. E. C. Rep. No. K-1469.

30. REINHOLD, G, 1963. Physik. Chem. 224(516): 384-418.

31. DRICKAMER, H. G., E. W. MELLOW \& L. H. TUNG. 1950. J. Chem. Phys. 18: 945.

32. POWERS, J. E. 1954. Univ. Calif. Rad. Lab. Rep. UCRL-2618.

33. BOYER, L. D. 1961. An experimental and theoretical investigation of vertical barriers in liquid thermal diffusion columns. Univ. of Oklahoma, $\mathrm{Ph}$. D. Thesis.

34. FLEMING, J. R. \& J. E. POWERS. 1963. A. I. Ch. E. J. 9(6): 730-40. 
35. HOF FMANN, T. \& A. H. EMERY, JR. 1963. A. I. Ch. E. J. 9(5): 653-9.

36. VICHARE, G. G. \& J. E. POWERS. 1962. A. I. Ch. E. J. 7: 650.

37. POWERS, J. E. 1961. Ind. Eng. Chem. 53: 577.

38. CROWNOVER, C. J. \& J. E. POWERS. 1962. A. I. Ch. E. J. 8: 166.

39. DRICKAMER, H. G., E. W. MELlow \& L. H. TUNG. 1950. J. Chem. Phys. 18: 945.

40. FLEMING, J. R. 1961. An investigation of the effect of horizontal barriers in a thermogravitational liquid thermal diffusion column, Univ. of Oklahoma. Ph.D. Dissertation

41. Liquid Thermal Diffusion. Aug. 1946. TID-5229 U. S. A. E. C. Oak Ridge, Tennessee.

42. NIER, A. O. 1940 Phys. Rev. 57: 30.

43. DRICKAMER. H. G., V. J. O'BRIEN, J. C. BRESEE \& C. E. OCKERT, 1948. J. Chem. Phys. 16: 122.

44. POWERS, J. E. 1961. Ind. Engr. Chem. 53: 577.

45. VAN DER VALK, F. 1963. Physica 29(5): 417-26, 427-36.

46. VRIES, A. E. \& M. F. LARANGEIRA. 1960. J. Chem. Phys. 32: 1714-16.

47. KRASNY-ERGEN, W. 1940. Phys. Rev. 58: 1078.

48. ECK, C. F., K. J. KAMINSKI \& M. A. WAKAT. 1964. MLM 1190.

49. TETSUYA, IIDA. 1957. Shoseki-Giho 1: 101-12.

50. SEelbach, C. W. \& F. W. QUaCkenbush. 1957. J. Am. Oil Chemists Soc. 34: $603-66$.

51. SAGERT, N. H. \& W. G. BRECK. 1961. Trans. Faraday Soc. 57: 436-46.

52. FISCHER, G. T. \& J. W. PRADOS. 1959. U. S. A. E. C. AECU 4125.

53. Grasselli, R., G. R. BRown \& C. E. Plymale. 1961. Chem. Engr. Prog. 57(5): $59-64$.

54. INDUSTRY AND ECONOMIC NEWS. Nov. 25, 1963. Chemical Engineering. 70: 64. 